\title{
Rancang bangun mesin press briket dari bahan serbuk kayu sistem pneumatik menggunakan 5 tabung percetak
}

\author{
Bambang Setiawan ${ }^{1 *}$, Rasma ${ }^{2}$ \\ Jurusan Teknik Mesin, Fakultas Teknik, Universitas Muhammadiyah Jakarta ${ }^{1,2}$ \\ Jl. Cempaka Putih Tengah 27 Jakarta Pusat \\ Email: bambang.setiawan@ftumj.ac.id, rasma@ftumj.ac.id
}

\begin{abstract}
At this time the Indonesian people are faced with various kinds of problems in terms of waste, if people have knowledge of the use of waste in the surrounding environment then this problem will be overcome, for example waste originating from coconut shells, wood, sawdust and palm shells that can used as charcoal and biomass fuel. In making briquettes with the dimensions and shape of briquettes that are uniform, then a tool designed with pneumatic technology. Because in pneumatic air pressure can be adjusted as needed. Pneumatic technology is a tool that can work (move) by utilizing air pressure from the compressor. Pneumatic works as movers, regulators, controllers and connect work processes.The advantages of pneumatic work systems are the availability of air that is not limited, easily distributed, flexibility, temperature, safe, clean, transfer of power and speed that is easily set. Based on the results of the design of the briquette maker on the process of making briquettes with a pneumatic system capable of speeding up the production time of briquette production and briquette size of $66 \mathrm{~mm}$ diameter and $100 \mathrm{~cm}$ height, determining the pressure on making briquettes that are uniform according to the weight and shape of the briquettes. Pressing the pressure of 6 bars produces a planned target product of 5 molding on wood briquette press machine but the results of the sawdust are broken and messy due to lack of adhesive and wood powder must be soft in small particles.
\end{abstract}

Keywords: briquette, pneumatic, and briquette making machine.

\begin{abstract}
Abstrak
Pada saat ini masyarakat Indonesia dihadapkan oleh berbagai macam permasalahan dalam hal limbah, jika masyarakat memiliki pengetahuan akan pemanfaatan limbah yang ada di lingkungan sekitar maka permasalahan ini akan dapat teratasi, contohnya limbah yang berasal dari batok kelapa, kayu, serbuk kayu dan cangkang sawit yang dapat dimanfaatkan menjadi arang dan bahan bakar biomassa. Dalam membuat briket dengan dimensi dan bentuk briket yang seragam maka dirancang alat yang berteknologi pneumatik. Karena dalam pneumatik tekanan udaranya dapat diatur sesuai kebutuhan. Teknologi pneumatik merupakan alat yang dapat bekerja (bergerak) dengan memanfaatkan tekanan udara dari kompresor. Pneumatik bekerja sebagai penggerak, pengatur, pengendali dan penghubung proses kerja. Keuntungan sistem kerja pneumatik adalah ketersediaan udara yang tidak terbatas, mudah disalurkan, fleksibilitas, temperatur, aman, bersih, pemindahan daya dan kecepatan yang mudah di atur. Berdasarkan hasil perancangan dari alat pembuat briket terhadap proses pembuatan briket dengan sistem pneumatik mampu mempercepat waktu produksi pembuatan briket dan ukuran briket diameter $66 \mathrm{~mm}$ dan tinggi $100 \mathrm{~cm}$, penentuan tekanan pada pembuatan briket yang seragam menurut berat dan bentuk briket. Dengan menekan tekanan 6 bar menghasilkan produk target yang direncanakan 5 moulding pada mesin press briket dari serbuk kayu tetapi hasil pada serbuk kayu pecah dan berantakan dikarenakan kurang nya perekat dan serbuk kayu harus lebih lembut serta partikel kecil.
\end{abstract}

Kata Kunci: briket, pneumatik, dan mesin pembuat briket. 


\section{Pendahuluan}

Pada saat ini masyarakat Indonesia dihadapkan oleh berbagai macam permasalahan dalam hal limbah, jika masyarakat memiliki pengetahuan akan pemanfaatan limbah yang ada di lingkungan sekitar maka permasalahan ini akan dapat teratasi, contohnya limbah yang berasal dari batok kelapa, kayu, serbuk kayu dan cangkang sawit yang dapat dimanfaatkan menjadi arang dan bahan bakar biomassa.

Saat ini permesinan yang sudah ada banyak di pasar sudah menggunakan sistem hidrolik dan screw akan tetapi belum sesuai hasil yang diharapkan. Dalam proses pemesinan secara sistem hidrolik menggunakan fluida cair bertekanan yang dialirkan dari pompa oli dengan tekanan sebesar 15 bar dengan kapasitas produksi sebesar $250 \mathrm{~kg} / \mathrm{hari}$. Bilamana bahan baku menjadikan terbatas proses produksi kurang efisien. Hasil pada produksi mesin dengan sistem hidrolik briket yang dihasilkan kurang berpori sehingga proses penyalaan api pada saat proses pembakaran memerlukan waktu yang relatif lama.

Terminal sirkuit pada sistem pneumatik dirancang agar apabila terjadi kebocoran lebih mudah diatasi dibanding dengan sistem hidrolik. Fluida sebagai media yang sensitif terhadap kebocoran minyak dan kontaminasi. Udara sebagai fluida pada sistem pneumatik memiliki tahanan dibandingkan sistem hidrolik Respon yang dihasilkan lebih cepat dibanding hidrolik. Fluida pada sistem hidrolik mudah tercemar oleh kotoran yang menyebabkan peralatan hidrolik menjadi lemah dan cepat rusak.

Dalam membuat briket dengan dimensi dan bentuk briket yang seragam maka dirancang alat yang berteknologi pneumatik. Karena dalam pneumatik tekanan udaranya dapat diatur sesuai kebutuhan. Teknologi pneumatik merupakan alat yang dapat bekerja (bergerak) dengan memanfaatkan tekanan udara dari kompresor. Pneumatik bekerja sebagai penggerak, pengatur, pengendali dan penghubung proses kerja. Keuntungan sistem kerja pneumatik adalah ketersediaan udara yang tidak terbatas, mudah disalurkan, fleksibilitas, temperatur, aman, bersih, pemindahan daya dan kecepatan yang mudah diatur [4].

\section{Tinjauan Pustaka}

\section{Asal usul briket arang}

Sebagai negara yang memiliki areal pertanian, perkebunan dan kehutanan yang sangat luas, limbah biomassa hasil pengolahan pertanian, perkebunan kehutanan yang ada di Indonesia terdapat dalam jumlah besar seperti kulit kacang, sekam padi, serbuk gergaji kayu, dan batok kelapa. Banyak yang tidak dimanfaatkan dibakar, dan dibuang sehingga dapat menyebabkan pencemaran lingkungan hidup dan merusak keseimbangan ekologis.

Secara tradisional arang merupakan bahan bakar rumah tangga yang banyak digunakan di pedesaan di Jepang, Eropa, Amerika dan Australia untuk memasak. Selain itu arang juga dimanfaatkan sebagai bahan bakar dan bahan baku untuk industri dan permintaan arang dari Jepang dan Korea Selatan saat ini terus meningkat.

Bahan baku dari briket menggunakan limbah-limbah sisa produksi, baik itu rumah tangga, perkebunan maupun sampah dari proses alam seperti daun-daun yang gugur. Proses pembuatan briket adalah proses pengolahan yang mengalami perlakuan penghalusan, pencampuran bahan baku, pencetakan dan pengeringan pada kondisi tertentu [6].

\section{Jenis -jenis briket}

Briket terdiri dari berbagai jenis dan bentuk sesuai dengan kandungan dan asalnya, antara lain adalah sebagai berikut:

a. Briket batubara

Briket batubara adalah bahan bakar padat dengan bentuk dan ukuran tertentu, yang tersusun dari butiran batubara halus yang telah mengalami 
proses penampatan dengan daya tekan tertentu. Agar bahan bakar tersebut lebih mudah ditangani dan menghasilkan nilai tambah dalam pemanfaatannya.

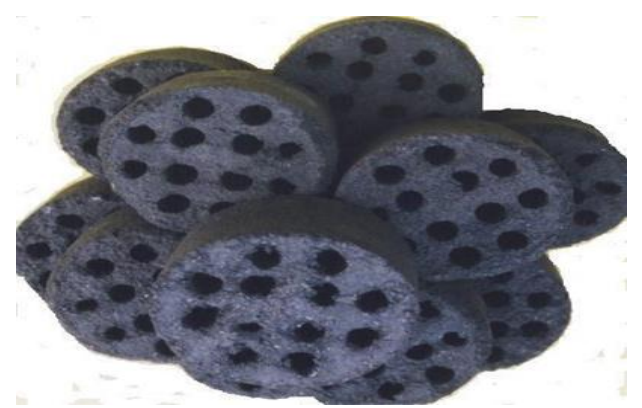

Gambar 1. Briket batubara

b. Briket arang tempurung kelapa

Tempurung merupakan lapisan keras yang terdiri dari lignin, selulosa, metoksil, dan berbagai mineral. Kandungan bahan-bahan tersebut beragam sesuai dengan jenis kelapanya. Struktur yang keras disebabkan oleh silikat (SiO2) yang cukup tinggi kadarnya pada tempurung.

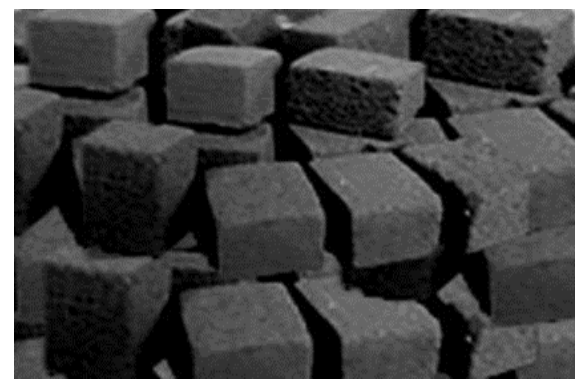

Gambar 2. Briket arang tempurung kelapa

Arang tempurung kelapa adalah produk yang diperoleh dari pembakaran tidak sempurna terhadap tempurung kelapa. Sebagai bahan bakar, arang lebih menguntungkan disbanding kayu bakar. Arang memberikan kalor pembakaran yang lebih tinggi dan asap yang lebih sedikit. Arang dapat ditumbuk, kemudian ditempa menjadi briket dalam berbagai macam bentuk. Briket lebih praktis penggunaannya dibanding kayu bakar.

c. Briket arang serbuk gergaji

Briket arang serbuk gergaji adalah energi alternatif yang terbuat dari hasil sisa-sisa penggergajian kayu. Dalam upaya pemanfaatan limbah serbuk gergaji, dimana serbuk gergaji merupakan bahan yang masih mengikat energi, oleh karena itu rantai pelepasan energi dimaksud diperpanjang dengan cara memanfaatkan serbuk gergaji sebagai bahan pembuatan briket arang.

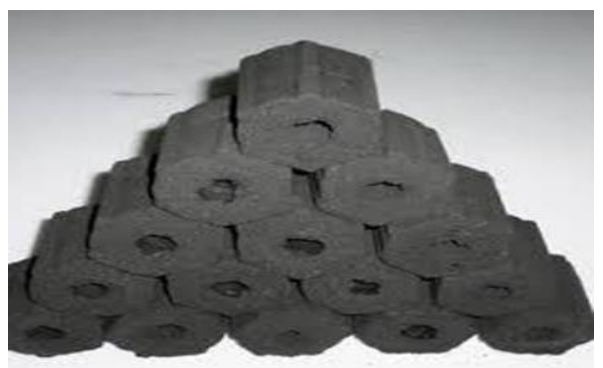

Gambar 3. Briket arang serbuk gergaji

Dengan penggunaan briket arang sebagai bahan bakar maka kita dapat menghemat penggunaan kayu sebagai hasil utama dari hutan. Selain itu penggunaan briket arang dapat menghemat pengeluaran biaya. Dengan memanfaatkan serbuk gergaji sebagai bahan pembuatan briket arang maka akan meningkatkan pemanfaatan limbah hasil hutan sekaligus mengurangi pencemaran udara, karena selama ini serbuk gergaji kayu yang ada hanya dibakar begitu saja [1].

\section{Metode Penelitan}

Perancangan ini dilakukan dalam beberapa tahapan yaitu meliputi perancangan alat dan pembuatan alat. Adapun diagram alir perancangan ditunjukkan pada gambar 4 . 


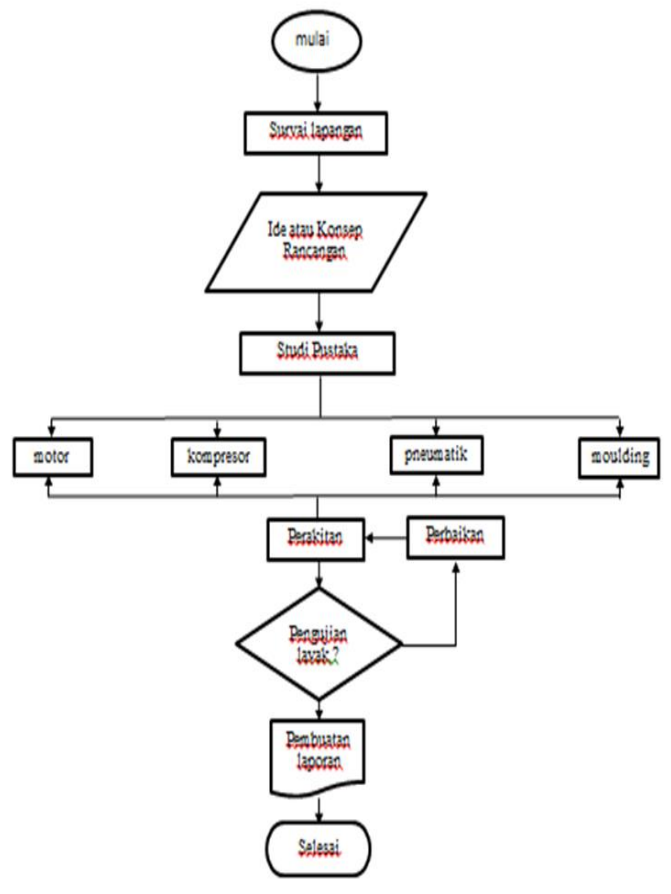

Gambar 4. Diagram Alir

\section{Alat dan bahan}

Alat yang digunkan dalam proses pembuataan alat press briket adalah:

\section{Alat}

1. Mesin las listrik

Las listrik berfungsi untuk menyambungkan benda logam dengan jalan menggunakan las busur listrik yang di aruskan ke permukaan logam yang akan disambung.

2. Meteran

Meteran digunakan untuk mengukur suatu rangka bangun.

3. Gerinda tangan

Mesin gerinda tangan digunakan untuk memotong bahan material serta menghaluskan bagian pinggir bahan material yang sudah dipotong.

\section{Bahan}

Bahan yang digunakan pada pembuataan alat mesin press serbuk arang adalah:

1. Kompresor ukuran $1 \mathrm{hp}$ (145 menit)

2. Selenoid Valve ukuran $\emptyset 3$ valve

3. Speed Control ukuran AS $42011 / 2$ inchi

4. Actuator ukuran CP 665 N 50x 100

5. Moulding ukuran $66 \times 100 \mathrm{~mm}$

6. Besi ukuran hollow 40x40x2mm [5].
Perancangan dan pembuatan

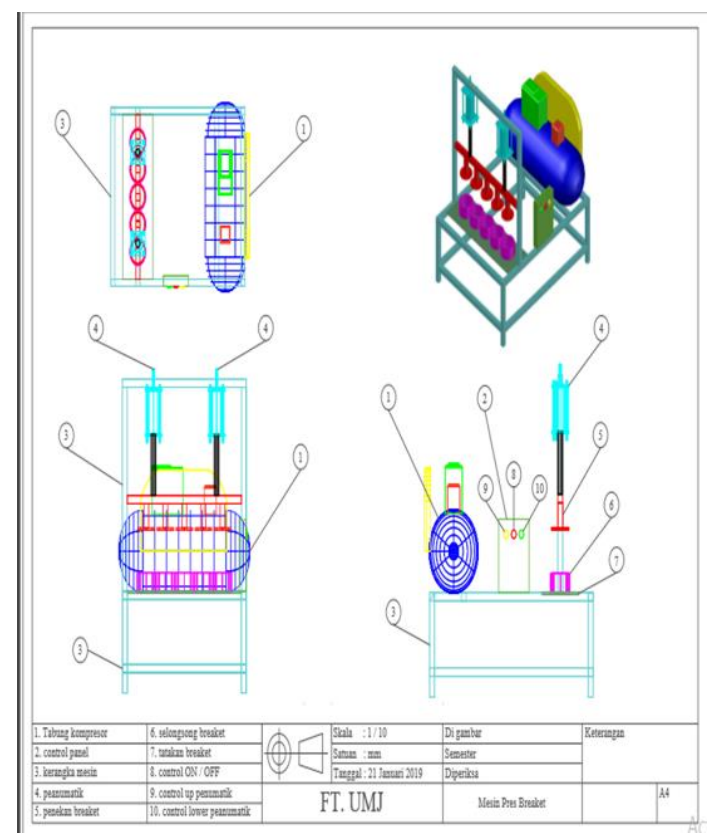

Gambar 5. Perancangan Mesin Fres

Mesin press briket serbuk arang tersebut digerakan Motor AC dengan daya $1 \mathrm{HP}$ putaran $2850 \mathrm{rpm}$, dan kompresor sebagai wadah tekanan udara dan ditransfer oleh selenoid valve, speed control, actuator yang digunakan adalah 2 buah untuk mentransmisikan tekanan udara pada actuator direncanakan 6 bar maka dari itu digunakan speed control transfer untuk menekan moulding pada serbuk arang kayu.

\section{Cara kerja mesin}

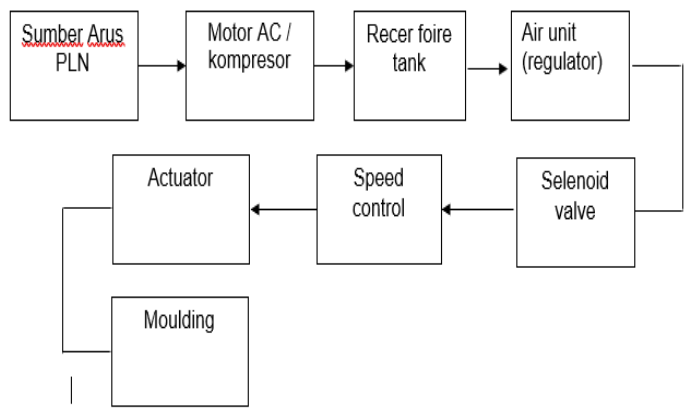

Gambar 6. Urutan cara kerja mesin fres

Cara kerja mesin press briket arang ini hampir sama dengan mesin press briket arang yang ada di pasaran. Pertama mesin disambungkan dengan sumber tengangan 220 Volt yang kemudian Motor AC berputar otomatis dan rice power tank penampung udara karena dihubungkan 
dengan menggunakan selenoid valve, speed control, dan actuator-nya [8].

\section{Pengujian pengepresan serbuk kayu}

Gaya press briket adalah data yang harus diketahui untuk memulai perhitungan perancangan mesin press briket serbuk kayu arang. Dalam menyusun penelitian ini, peneliti menguji serbuk kayu yang kering sebagai bahan utamannya melakukan uji coba dengan beberapa kali percobaan menggunakan penumatik sebagai uji pengepresan tersebut, caranya serbuk kayu diberi perekat atau lem untuk merekat serbuk kayu tersebut berantakan dan pnemuatik diberi alat tambahan seperti tumbukan tersebut bisa utuh di dalam moulding. Pada regulator diatur tekanan angin sehingga penumatik bisa bergerak maju dan mundur [6].

Tabel 2. Hasil pengujian pengepresan serbuk kayu dengan sistem peneumatik

\begin{tabular}{ccc}
\hline $\begin{array}{c}\text { Tekanan } \\
(\text { bar })\end{array}$ & $\begin{array}{c}\text { Jarak } \\
(\mathrm{cm})\end{array}$ & $\begin{array}{c}\text { Hasil } \\
(\mathrm{cm})\end{array}$ \\
\hline 1 & 100 & 21 \\
\hline 6 & 100 & 50 \\
\hline
\end{tabular}

Hasil dari percobaan terhadap pengepresan serbuk kayu di atas dari percobaan tersebut maka diambil tekanan sebesar 6 bar untuk mmenumbukkan 5 buah moulding dengan hasil penuh menjadi $50 \%$ dari $100 \mathrm{~cm}$ sehingga gaya yang dibutuhkan adalah.

Gaya pengepresan serbuk kayu:

$$
\mathrm{P}=\frac{\mathrm{F}}{A}
$$

Dik: $\mathrm{P}=6$ bar $=600000 \mathrm{~N} / \mathrm{m}^{2}$

$$
\text { Diameter moulding }=66 \mathrm{~mm}=
$$
$0,066 \mathrm{~m}$

- Pertama mencari A (luas penampang)

$$
\begin{aligned}
& \mathrm{A}=\frac{\pi D^{2}}{4} \\
& \frac{3,14 \times 0,066^{2}}{4} \mathrm{~m}^{2} \\
& \mathrm{~A}=0,00341946 \mathrm{~m}^{2}
\end{aligned}
$$

- Gaya pada piston pneumatik $F=A . P$

$$
\begin{aligned}
& F=0,00341946 \mathrm{~m}^{2} \times 600000 \mathrm{~N} / \mathrm{m}^{2} \\
& F=2051,67 \mathrm{~N}=2,052 \mathrm{kgf}
\end{aligned}
$$

\section{Perencanaan diameter silinder pneumatik}

Untuk mencari diameter silinder pneumatik minimal yang akan dibutuhkan, maka pada perencanaan awal diambil tekanan kerja dari sistem $6 \mathrm{kgf} / \mathrm{m}^{2}$, dan gaya pembentukan embosing sebesar 2,052 kgf. Sedangkan untuk nilai $\mu$ diambil 0,85 (tenaga fluida pneumatik). Data ini kemudian dipakai dalam perencanaan silinder pneumatik untuk pengembosan.

Diameter minimal dapat dicari dengan persamaan:

$$
\mathrm{F}=\mathrm{D}^{2} \cdot \frac{\pi}{4} \cdot p \cdot \mu
$$

Maka dari persamaan di atas dapat direncanakan piston sebagai berikut :

$$
\begin{aligned}
& \mathrm{F}=2,052 \mathrm{kgf} \\
& \mathrm{p}=6 \mathrm{kgf} / \mathrm{cm}^{2} \\
& \mu=0,85 \\
& \mathrm{~F}=\mathrm{D}^{2} \cdot \frac{\pi}{4} \cdot \rho \cdot \mu \\
& 2,052 \mathrm{Kgf}=\mathrm{D}^{2} \frac{3,14}{4} \cdot 6 \mathrm{kgf} / \mathrm{cm}^{2} \cdot 0,85
\end{aligned}
$$

$\mathrm{D}^{2}=\frac{2,052 \mathrm{Kgf}}{4,0035 \mathrm{Kgf} / \mathrm{cm}^{2}}$

$\mathrm{D}^{2}=0,512 \mathrm{~cm}^{2}$

$\mathrm{D}=\sqrt{0,512} \mathrm{~cm}^{2}$

$\mathrm{D}=0,715 \mathrm{~cm} \approx 71,5 \mathrm{~mm}$

Dari perencanaan di atas didapat diameter minimal silinder pneumatik sebesar 71,5 mm. Maka untuk perencanaan ini dipilih silinder dengan diameter $66 \mathrm{~mm}$ dengan double acting cylinder karena diperlukan gerakan maju mundur [4].

\section{Gaya dorongan silinder}

Gaya dorongan silinder dapat diketahui sebagai berikut:

$$
\mathrm{F}=\mathrm{D}^{2} \cdot \frac{\pi}{4} \cdot p \cdot \mu
$$

Dengan data yang telah diketahui:

$$
\begin{aligned}
& \mathrm{D}=66 \mathrm{~mm}=0,066 \mathrm{~m} \\
& \mathrm{~d}=64 \mathrm{~mm}=0,064 \mathrm{~m} \\
& \mathrm{p}=6 \mathrm{kgf} / \mathrm{m}^{2} \\
& \mu=0,85 \mathrm{Maka}, F_{1}=\frac{\pi}{4} \cdot D^{2} \cdot p \cdot \mu
\end{aligned}
$$




$$
\begin{aligned}
F_{1} & =\frac{3,14}{4}(0,066 \mathrm{~m})^{2} \cdot 6 \\
& \mathrm{Kgf} / \mathrm{m}^{2} \cdot 0,85 \\
F_{1} & =0,2080 \mathrm{Kgf}
\end{aligned}
$$

\section{Gaya tarikan silinder}

Gaya tarikan silinder dapat diketahui dengan menggunakan persamaan:

$$
\begin{aligned}
& F_{2}=\frac{\pi}{4}\left(D^{2}-d^{2}\right) \cdot \rho \cdot \mu \\
& F_{2}=\frac{3,14}{4}\left(0,066^{2}-0,064^{2}\right) \cdot 6 \mathrm{kgf} / \mathrm{m}^{2} \cdot 0,85 \\
& F_{2}=\frac{3,14}{4}\left(0,004356 \mathrm{~m}^{2}-0,004096 \mathrm{~m}^{2}\right) \cdot 6 \mathrm{kgf} / \mathrm{m}^{2} \cdot 0,85 \\
& F_{2}=0,00104091 \mathrm{kgf}
\end{aligned}
$$

\section{Perhitungan daya kompresor}

$$
\begin{aligned}
& \text { Diketahui udara }=3,252 \\
& \text { ltr } / \mathrm{mnt} \text { Tekanan pengukuran }=6 \mathrm{bar} \\
& \text { Efisiensi }=95 \% \\
& P_{\text {output }}=Q_{v} \times P_{e} \\
& =0,003252 \mathrm{~m}^{3} / \mathrm{mnt} \times 600000 \mathrm{~N} / \mathrm{m}^{2} \\
& =1,9512 \mathrm{Nm} / \mathrm{s} \\
& =0,032 \mathrm{Nm} / \mathrm{s} \approx 0,032 \text { watt } \\
& P_{\text {motor }}=\frac{P_{\text {output }}}{\eta} \\
& =\frac{0,032}{0,95} \\
& =0,033 \text { watt }
\end{aligned}
$$

Untuk pengaman diambil sebesar $1 \mathrm{HP}$ pada daya kompresor.

\section{Perhitungan kecepetan silinder}

Pesarnya kecepatan silinder didapatkan dari percobaan saat silinder extand dengan menggunakan persamaan

Keterangan ,

$$
\mathrm{V}=\frac{s}{t}
$$

$\mathrm{V}=$ kecepatan piston $(\mathrm{m} / \mathrm{s})$

$\mathrm{S}=$ panjang stroke $(\mathrm{m})$

$\mathrm{t}=$ waktu langkah $(\mathrm{s})$

Dari data yang diketahui

$\mathrm{S}=100 \mathrm{~mm}=0.1 \mathrm{~m}$

$\mathrm{t}=3 \mathrm{~s}$ maka $\mathrm{V}=\frac{0,1 \mathrm{~m}}{3}=0,033 \mathrm{~m} / \mathrm{s}$

\section{Pemilihan kompresor}

Dari data tekanan dan kapasitas silinder di atas maka kompresor yang dipilih adalah tipe reciprocting compressor karena tipe ini sering digunakan pada sistem pneumatik dan memiliki tekanan stabil. Selain itu kompresor jenis ini mempunyai tekanan yang rendah sampai tinggi perhitungan kapasitas kompresor:

Tekanan operasi $6 \mathrm{bar}=6 \mathrm{kgf} / \mathrm{cm}^{2}$

$6 \mathrm{kgf} / \mathrm{cm}^{2}$ x $\frac{2,2046 \mathrm{lbf}}{1 \mathrm{kgf}}=13.2276 \mathrm{lbf} / \mathrm{cm}^{2}$

$\mathrm{x} \frac{1 \mathrm{~cm}^{2}}{0,155 \mathrm{In}^{2}}=85,339 \mathrm{lbf} / \mathrm{in}^{2}$

Dari perhitungan di atas, diketahui kapasitas kompresor yang dibutuhkan sebesar 100 psi.

\section{Kapasitas udara}

Kapasitas udara dapat dihitung:

$$
\begin{aligned}
\mathrm{Q} & =D^{2} \cdot \mathrm{V} \cdot \mathrm{Cr} \\
& =(0.066 \mathrm{~m})^{2} \cdot 0.033 \mathrm{~m} / \mathrm{s} \cdot 7,9 \\
& =0,001136 \mathrm{~m}^{3} / \mathrm{s}
\end{aligned}
$$

Jadi data-data sebelumnya dimasukkan

$$
\begin{aligned}
L_{\text {total }} & =2 \mathrm{~m} \\
\mathrm{Q} & =0,001136 \mathrm{~m}^{3} / \mathrm{s} \\
& =0,066 \mathrm{~m}
\end{aligned}
$$

maka didapatkan :

$$
\begin{aligned}
\Delta p & =\frac{1,6 \times 10^{3} \times \mathrm{Q}^{1,85} \times \mathrm{L}}{\mathrm{d}^{5} \times \mathrm{p}} \\
\Delta p & =\frac{1,6 \times 10^{3} \times 0,001136^{1,85} \times 2}{0,066^{5} \times 6.10^{5}} \\
\Delta p & =\frac{0,0113997}{0,7514} \\
\Delta p & =0,015173 \mathrm{~Pa} \\
\Delta p & =1,517 \text { bar }
\end{aligned}
$$

Jadi, kerugian tekanan pada pipa sebesar 1,517 Bar

\section{Pencampuran bahan serbuk kayu dan oli}

Sebelum dilakukan pencampuran serbuk kayu dan oli terlebih dahulu mempersiapkan bahan serbuk kayu, oli bekas untuk merekat mempercetak bahan untuk pembuatan arang dari serbuk kayu, dengan ukuran pas antara pencampuran pada oli dengan serbuk kayu kasar. Dapat dilihat pada gambar berikut.

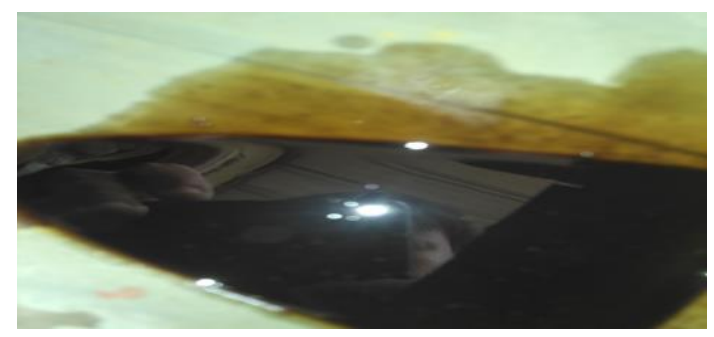

(A) 


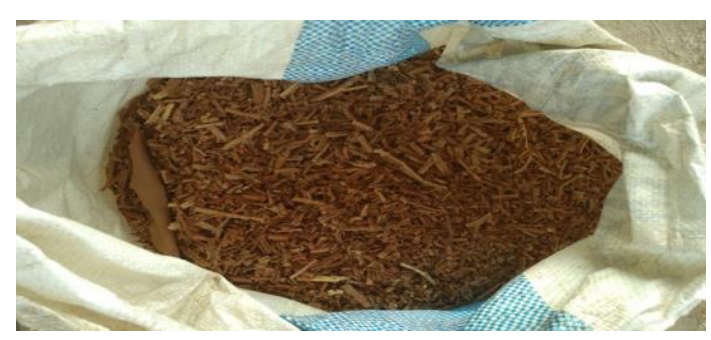

(B)

Gambar 7. Bahan Yang Sudah Tercampur Oli

\section{Hasil uji produktivitas mesin press briket}

Hasil waktu yang diperoleh pada saat pengujian press briket dapat dilihat pada tabel 3 .

Tabel 3. Hasil tekanan pada sistem pneumatik

\begin{tabular}{ccc}
\hline $\begin{array}{c}\text { Tekanan } \\
(\text { bar })\end{array}$ & $\begin{array}{c}\text { Jarak } \\
(\mathrm{cm})\end{array}$ & $\begin{array}{c}\text { Hasil } \\
(\mathrm{cm})\end{array}$ \\
\hline 1 & 100 & 21 \\
\hline 2 & 100 & 33 \\
\hline 3 & 100 & 38 \\
\hline 4 & 100 & 42 \\
\hline 5 & 100 & 48 \\
\hline 6 & 100 & 50 \\
\hline
\end{tabular}

Dengan memberi tekanan 6 bar menghasilkan produk target yang direncanakan 5 moulding pada mesin press briket dari serbuk kayu tetapi hasil pada serbuk kayu pecah dan berantakan dikarenakan kurangnya perekat dan serbuk kayu harus lembut serta partikel yang kecil-kecil.

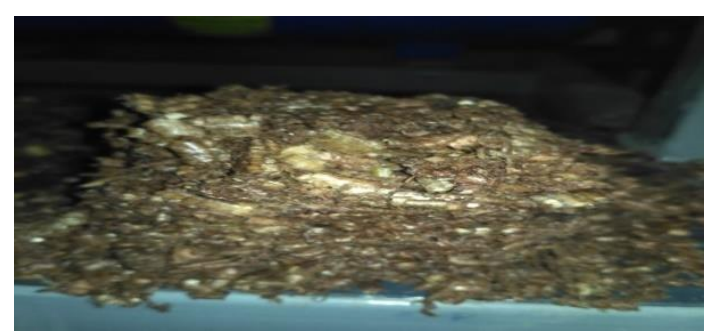

Gambar 8. Hasil serbuk kayu berantakan

\section{Kesimpulan}

Berdasarkan rancang bangun mesin press briket dari bahan serbuk kayu sistem pneumatik menggunakan 5 tabung percetak maka dapat disimpulkan bahwa daya yang diperlukan untuk kompresor adalah 0,033 Watt dan untuk pengaman daya diambil sebesar 0,75 HP. Kebutuhan konsumsi udara yang dibutuhkan silinder dengan $\mathrm{D}=66 \mathrm{~mm}$ dan panjang langkahnya $100 \mathrm{~mm}$ untuk mengerak maju dan mundur pneumatik sebesar 3,252 ltr/mnt dan untuk menekan pada mesin press briket menggunakan tekanan sebesar 6 bar. Hasil dari produksi yang diperoleh mesin press briket dengan metode pneumatik dapat dikatakan kurang baik dikarenakan tidak merata dalam pembentukan briket.

\section{Referensi}

[1]. Daud Patabang, 2012, "Karakteristik termal briket arang sekam padi dengan variasi bahan perekat".

[2]. Esposito, A. 2003, "Fluid Power with Application", sixth edition, Prentice Hall International Inc, New Jersey 3.

[3]. Himawanto, et al, 2015, Pengolahan Limbah Industri Aren Sebagai Bahan Bakar Alternatif: Karakteristik Pembakaran, Jurnal Ilmiah Enviro, Diterbitkan Maret 2016.

[4]. Krist, Thomas. 1993, "Dasar-dasar Pneumatik", Austria, Erlangga, Jakarta.

[5]. Michael samuel. 2016, dengan judul "Modifikasi alat pencetak briket arang dengan sistem press hidrolik menggunakan bahan baku limbah teh"

[6]. Muhammad Fajar Arfani, Lukman Adlin Harahap, Adian Rindang, 2015, dengan judul "Rancang bangun alat pencetak briket arang berbahan dasar limbah teh".

[7]. Majumdar, S.J (1995), "Pneumatic System Principle and Maintenance", First Edition, McGraw Inc 2.

[8]. Muhamad Andri Destrian. 2010. Prototipe Mesin Alur Kayu Berbasis Kendali Pneumatik. Skripsi Sarjana1, Jurusan Teknik Industri, Fakultas Teknik, Universitas Sebelas Maret, Surakarta. 
[9]. Roro Heni Hendaryati dkk, 2017, dengan judul "Rancang bangun mesin briket skala rumah tangga",

[10]. The Pneumatic Technical Centre (1991), "Tenaga Fluida Pneumatik Pembelajaran Tingkat Menengah" 